\title{
Analysis and numerical modelling of dynamic ground support based on instrumented full-scale tests
}

\author{
A Roth Geobrugg AG, Switzerland \\ M Cala AGH University of Technology and Science, Poland \\ R Brändle Geobrugg AG, Switzerland \\ E Rorem Geobrugg North America, USA
}

\begin{abstract}
Ground support for dynamic conditions must be able to withstand the associated loads and deformations and the support scheme has to work as a system. In order to prove the suitability of such support systems with mesh and bolts, and to also analyse the bearing behaviour of them, a full scale test setup was commissioned in 2012 in Walenstadt, Switzerland. On this test rig it is possible to apply large energies on a ground support scheme with four dynamic bolts and a mesh panel of $2.4 \times 2.4 \mathrm{~m}$ in a full-scale way. The test site is highly instrumented, and in this paper the analysis of the load cells, the accelerometers and the high speed video cameras is given. It can be shown that the bolts as the stiffest elements are always loaded first and then load is transferred to the surface support during the stopping process. Together with the numerical modelling and back calculation of the tests, it is possible to learn more about the stopping process of dynamic loading of ground support and consequently determine the load and energy distribution between the components. The full-scale tests show that stiff bolts and also mesh which is able to stop high loads at low deformations are required to withstand large dynamic loading without substantial deformations during a seismic event.
\end{abstract}

\section{Introduction}

As more and more near surface deposits are mined out, deeper mines are required in order to continue the exploitation of resources. This inevitably leads to the occurrence of more rockbursting, deformation problems and safety issues. Rockburst means stress induced loosening of parts of the rock mass under enormous energy release. It seems to be similar to damage from natural seismic phenomena. Rockburst events occur mostly in deep tunnels and mines but also in shallower mines in regions with high horizontal stresses.

There are different methods to mitigate rockburst risks thus reducing exposure of personnel. Changes include mine design layout and extraction sequence (Potvin 2012). In addition the ground support needs to be chosen and designed in such a way that it can cope with the conditions. In deep mines, the ground support is complex and cost is high. Static ground support is not satisfactory for such a demanding environment. The ground support consists of the rock reinforcement (e.g. bolt), a surface support element (e.g. mesh) and the connection between the two (e.g. plate). For dynamic loads, it is essential that these components fit and work together as a system (Cala \& Roth 2007). The observations of (Heal 2010) show that most of the damage done from rockbursting led to the failure of the surface support or the rupture of the reinforcement.

In order to investigate the dynamic behaviour of reinforcement elements and surface support, extensive testing was carried out at various test sites. Some tests were done in South Africa, Canada and Australia. Hadjigeorgiou and Potvin (2011) put the results of the various tests together and tried to make them comparable. However the boundary conditions of the test sites were different making comparison difficult. 
There are two active test sites at the moment, one is in Canada at CANMET and the other in Australia at the Western Australian School of Mines (WASM) (Player \& Villaescusa 2004). The WASM test site is the best instrumented facility and is based on the momentum transfer concept. It can test reinforcement, surface support and to a certain extent combinations of the two.

\section{Motivation}

Mining engineers design support systems for their operations, based on the work done in Canada which resulted in the 'Canadian Rockburst Manual' (Kaiser et al. 1996) and the aforementioned testing of reinforcement and surface support. It is widely known that the support scheme should work together, but there is little research data available on the dynamic interaction of the main components. In many cases the energy absorption capacities are added together in a superposition for obtaining the capacity of the system as a whole.

Both in static and dynamic loading, it is important that the surface support can bear the load of the rock mass and transfer it to the reinforcement. Furthermore in dynamic loading, the reinforcement should start yielding in order to absorb energy without the surface support failing beforehand. Heal (2010) comes to the conclusion that using the dynamic capacity of the reinforcement alone for the design would likely overestimate the capacity of the system. Potvin (2012) therefore proposes to look at the weakest link of the support system and since this is in most cases the surface support, makes the assumption to use the capacity of the surface support as the capacity of the system.

In this study it is believed that the above mentioned approach is too conservative and that more data on the interaction between the reinforcement, the surface support and the connection elements is required. This is one reason for using the test site in Walenstadt, Switzerland, where a $3.6 \times 3.6 \mathrm{~m}$ surface support can be dynamically tested with four dynamic rockbolts in a regular bolt pattern. The other motivation comes from the need to translate the results of the individual component tests at test sites like the WASM site (Player \& Villaescusa 2004) into full-scale tests for proving the suitability and fitness for use of the overall system. Another option is to use blast tests for this (Heal et al. 2004), but there the loading is questionable and the testing is hardly repeatable.

The hypothesis of this work is based on the assumption that during dynamic loading of a surface support scheme, the surface support is loaded by a part of the fractured mass. The resulting force in the surface support will then be transferred to the connection element (e.g. plate) and then on to the reinforcement, with the other part of the load going directly to the reinforcement. The rock mass around the bolt is bonded to the bolt and held by the plate. There will be an arching effect in the rock mass in between the bolts, depending on the fracturing. Consequently part of the loading will go directly on the bolts and not on the mesh. To verify the difference in loading, load cells were used in the test setup at both ends of the bolts. It is the aim of the test setup to measure the loads in the different elements and then back calculate what load was borne by the surface support and how much was carried by the dynamic reinforcement directly (Cala \& Roth 2013). This is, of course, dependent on the type of rock mass and cannot be seen as a general ratio.

For these large scale field tests and their analysis, the calculation of the energy output during a rockburst event is the main topic. Additionally important, is the development of adequate retaining elements such as reinforcement and surface support. Their behaviour during rockbursts has to be proven and their interaction has to be observed and described. The test construction should be able to test interaction, and show how much energy will be absorbed by reinforcement, surface support and the test setup itself. This may be compared to the breakage of the rock in a real rockburst event which also absorbs energy.

\section{$3 \quad$ Large scale field tests}

Many tests regarding the behaviours of dynamic reinforcement and surface support alone have been carried out already. Thus, the behaviour of the individual retaining elements is well known. But for safety in tunnelling and mining projects, it is of great interest to have a complete support scheme which protects the 
underground workers from risks, such as rockbursts. These large scale field tests are supposed to show the behaviour of dynamic high tensile mesh and dynamic rockbolts installed together. The tests should indicate the load and energy distribution between the components.

\subsection{Test setup}

The main frame of the test setup is made of steel, with a high tensile chain link mesh horizontally connected to the frame by lacing wire rope through mesh and the frame (Figure 1). The mesh is held by four dynamic rockbolts in a typical pattern.
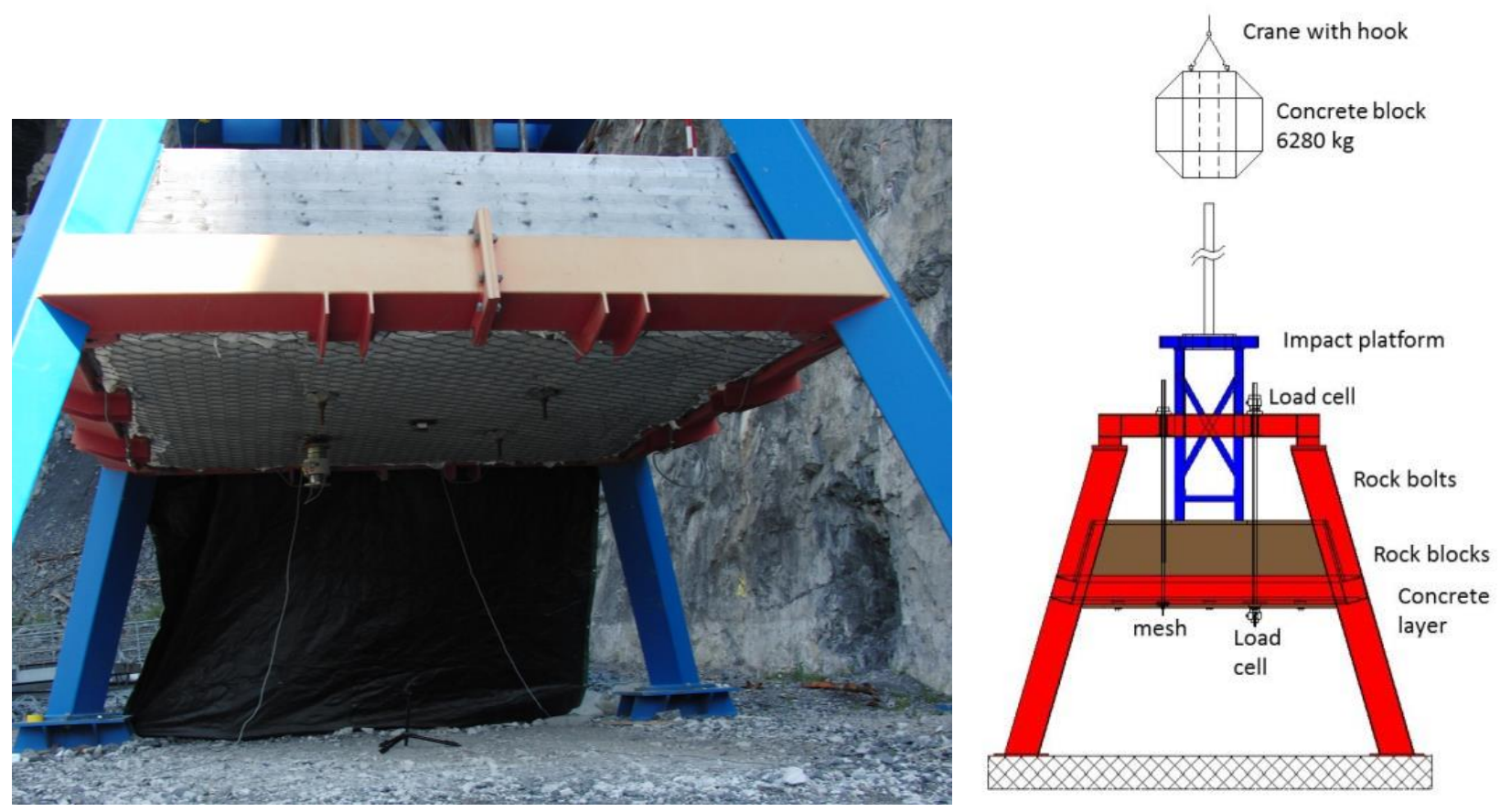

\section{Figure 1 Large scale field test setup}

Formwork was installed underneath the wire mesh. A plastic foil was placed on top of the wire mesh, before concrete was poured onto the formwork. The plastic foil was used to keep the mesh separated from the concrete slab. Before the tests were conducted, the plastic foil was removed. Natural rock boulders and an equalising layer of gravel were then placed on the top of the thin concrete slab. This layered build-up of concrete, rocks and gravel is intended to simulate the pre fractured rock mass prior to the rockburst, with the concrete plate as a base to prevent mesh and bolts from preloading. The concrete slab is designed to crack under load as there is no reinforcement in the concrete. On top of the gravel layer, a load distribution plate is installed to initiate the energy impact caused by the test block's impact. The test block is lifted by a crane. To start the test, the crane will disengage the test block which then falls onto the impact platform on the top of the construction. The impact platform on the steel stamp is connected with the load distribution grid lying on the equalising gravel layer.

While following physical laws, the energy impact on the whole construction is the difference of the potential energy of the test block before and after the impact. The maximum height to lift the test block is limited by the length of the guiding steel column to approximately $3.25 \mathrm{~m}$ (Figure 1). The mass of the test block used is $6,280 \mathrm{~kg}$.

For the rockburst trials, a high tensile steel wire mesh of $3.6 \times 3.6 \mathrm{~m}$ (mesh type TECCO G80/4, aperture $80 \mathrm{~mm}$, wire diameter $4 \mathrm{~mm}$, wire strength $1,770 \mathrm{~N} / \mathrm{mm}^{2}$ ) and four dynamic rockbolts of $3 \mathrm{~m}$ length (bolt type D-Bolt, diameter of $20 \mathrm{~mm}$ ) were used. The dynamic bolts have a deformable length of $1.5 \mathrm{~m}$ and according to the manufactures' specification would elongate by about $15 \%$, meaning an elongation of about $225 \mathrm{~mm}$ is possible. The bolts were grouted into steel tubes (wall thickness $8 \mathrm{~mm}$ ) which are separated into two parts. This gives a defined position for the elongation of the bolt (simulating the 
detachment point of the fractured rock mass). For the load transmission from the mesh to the bolts, special spike plates (Figure 2) are used whose geometry fits exactly to the diamond shaped steel wire mesh. The spike plates ensure that six wires are always grasped by each plate.

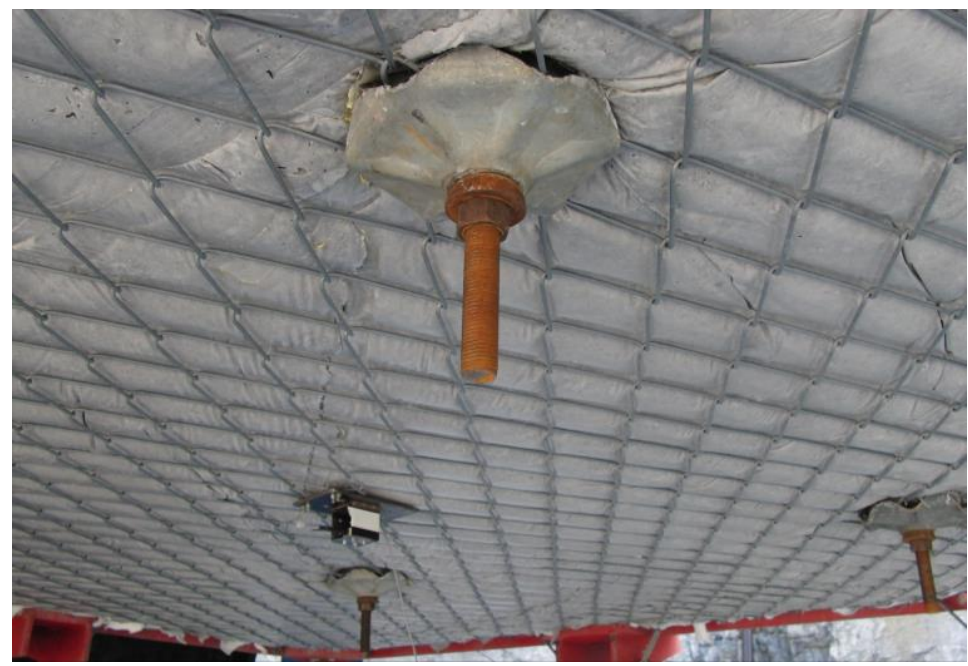

\section{Figure 2 Special spike plates}

\subsection{Instrumentation}

In order to determine factors affecting the system, devices including load cells and high speed cameras were installed to evaluate the distribution of the forces on the mesh, bolt and system as a whole.

The forces and the elongation of the bolts, as well as the deflection of the mesh are the primary factors used to calculate the energy absorption capacity of the mesh and the bolts. Based on the results from the test, the energy capacity of the elements can be calculated by the area under the load-displacement curve. By knowing the input energy calculated by the potential energy difference of the test block before and after the impact, the energy absorbed by the test setup can be back calculated.

\subsubsection{Load cells}

Two load cells were installed on one of the four dynamic bolts. One cell is at the collar of the bolt, the other one at its toe end (Figure 3). The upper cell (toe) measures the total force on anchor and mesh together while the lower cell (collar) only measures the vertical load taken up by the mesh.

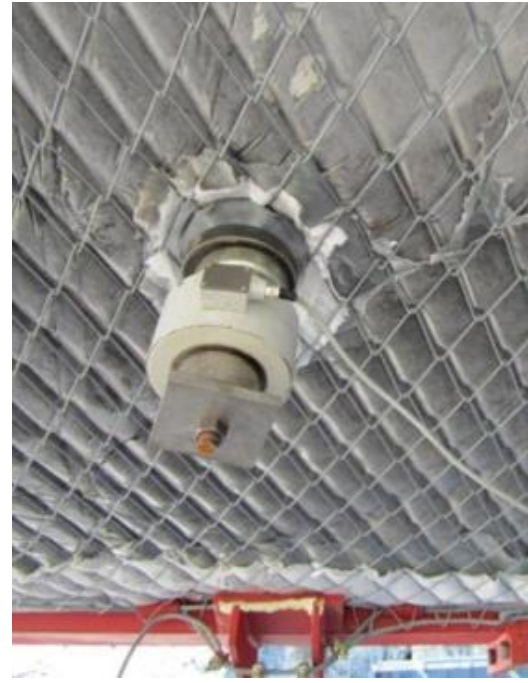

(a)

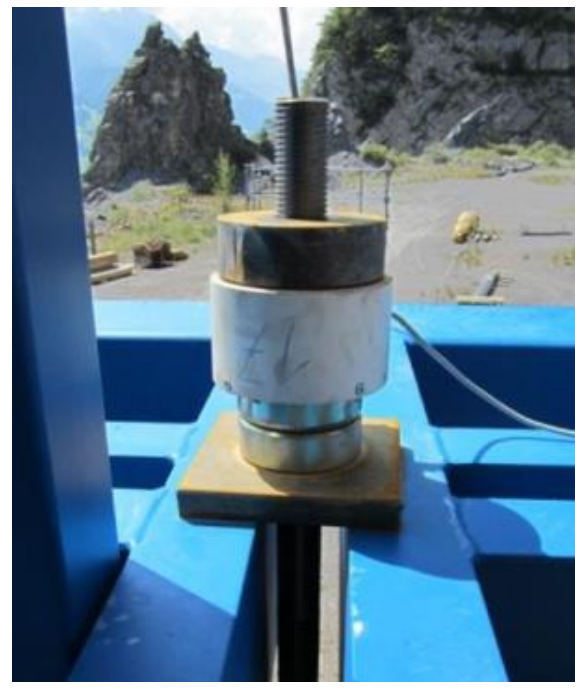

(b)

Figure 3 (a) lower collar; and (b) upper toe load cell 


\subsubsection{High speed cameras}

Two high speed cameras were installed in front of the steel frame, from where several measuring points on the bolts, the mesh and the test block were filmed. With a computer tracking program, the displacement of mesh and bolts can be evaluated from the grouped pictures per time by tracking a measuring point on the pictures. The velocity can be calculated by the first differentiation of the displacement and the acceleration by the second differentiation of the displacement. The upper camera films the movement of the test block and the impact, whilst the lower camera films the deformation of the mesh and bolts.

\subsection{Test execution}

As already mentioned in Section 3.1, a rockburst is simulated by releasing a heavy concrete test block in free-fall on the test setup. Due to the potential energy difference of the test block before and after the impact, a certain amount of energy is put into the system. This energy is absorbed by the bolts, the mesh and the test set up itself (including breakage of the concrete slab).

After the dynamic movement of the rock mass, the effect of plastic elongation and deformation of bolts and mesh is evident. All the extra elastic deformation can be determined by analysing the data output from high speed cameras and accelerometers. This shows the maximum deformation of the support elements during the dynamic impact.

Different tests were carried out with various stiffness levels for the assembly, mainly by varying the thickness of the concrete slab and the assembly of the natural stones which are built-in more or less interlocked. Those adjustments resulted in different loading conditions of the anchors and the mesh which directly refers to the variable behavior of rock masses in reality.

The following pictures show the plastic deformation of the mesh and the bolts. Firstly, for a stiff assembly, and secondly, for a softer one.

For the stiff setup, the elongation of the bolts is very well seen (Figure 4(a)). The elongation was $150 \mathrm{~mm}$, or $10 \%$ of the dynamic length of the bolt. As noted above, the bolts used in this test are able to elongate to about $15 \%$ of their length.

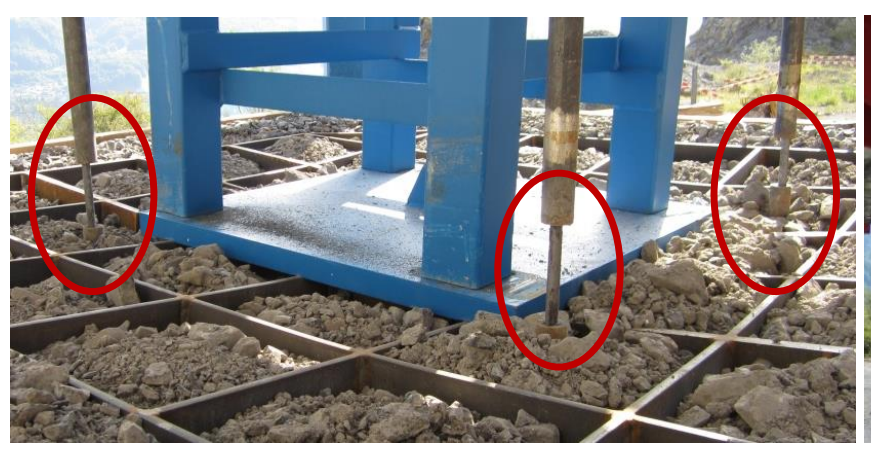

(a)

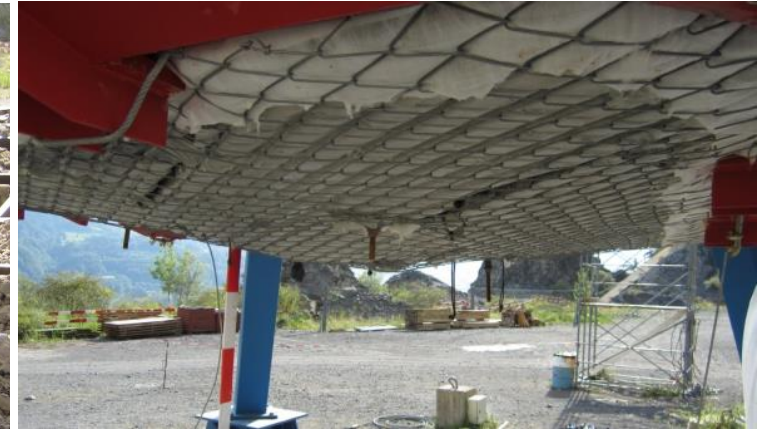

(b)

\section{Figure 4 (a) elongation of anchors for a stiff assembly; and (b) pressing of the concrete plate into the mesh for a stiff assembly}

For the stiff assembly, the deflection of the mesh was about $140 \mathrm{~mm}$ which is quite moderate (Figure 4(b)). Due to the thickness, and therefore stiffness, of the concrete slab, the slab only broke up into a few large pieces. Therefore, the loading on the mesh was not in a parabolic shape as expected with more fragmented rock. The shape had a more triangular character due to the big concrete pieces pressed into the mesh. This loading results in higher forces on the bolts compared to the forces on the mesh and therefore, in combination with the major deformation of the mesh, to more energy absorption by the bolts than by the mesh. 

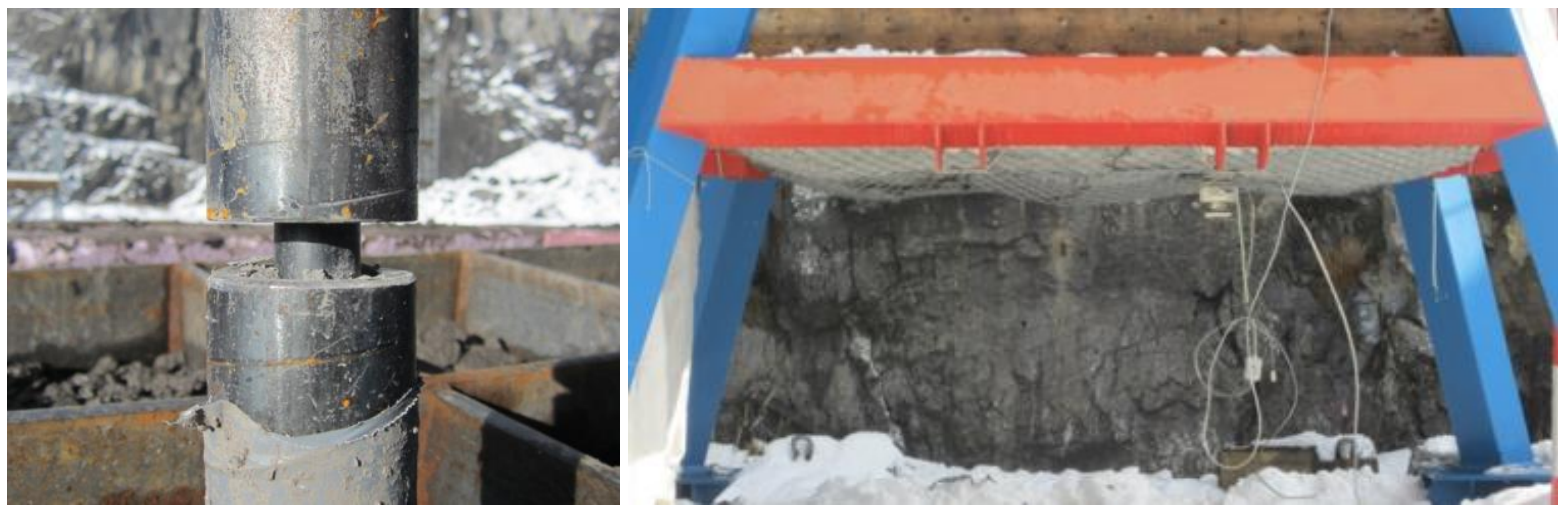

Figure 5 (a) elongation of anchors for a softer assembly; and (b) deflection of the mesh for a softer assembly

The nearly parabolic shape can be noticed, when looking at the deflection of the mesh of the softer setup (Figures 5(b) and 6). At its highest deformation, the deflection of the mesh is around $300 \mathrm{~mm}$.
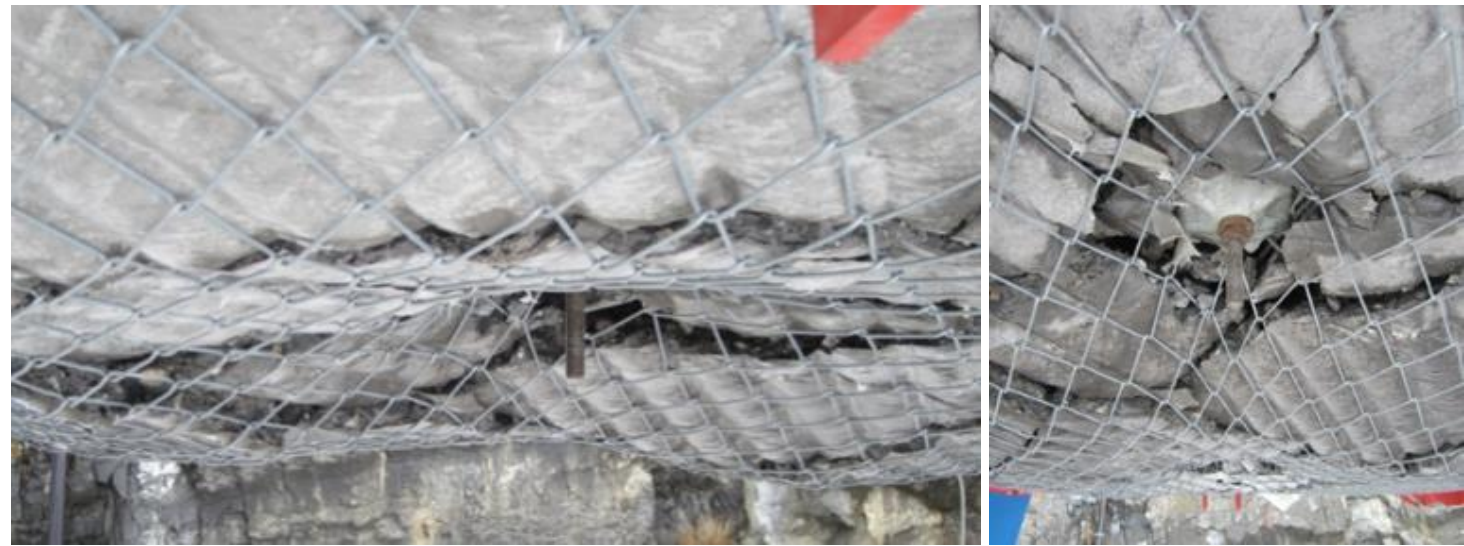

Figure 6 Loading of the mesh and transferring the loads to the plates

In comparison, when the test was setup with a thinner and less stiff concrete slab, the loading on the mesh resulted in a more parabolic shape, due to the higher fracturing rate in the concrete. As a consequence, the plate and bolt only see the loading from the cone shaped material directly above the bolt and plate. In this test setup the mesh absorbs more energy than the bolts. Figure 5(a) shows the movement of the bolts of about $25 \mathrm{~mm}$ for the softer setup.

\subsection{Multi-impact test}

A multi-impact test was conducted with five impacts having the same test setup. The goal of the test was to bring the bolts to their maximum elongation and failure. Thus load distribution and behavior of the mesh and bolts during high anchor elongation was investigated. Support capacity of the mesh net without bolt support was calculated at impact number five where all bolts broke (Figure 7). Due to the setup, it was not possible to measure the loads in the mesh after breaking of the bolts. 


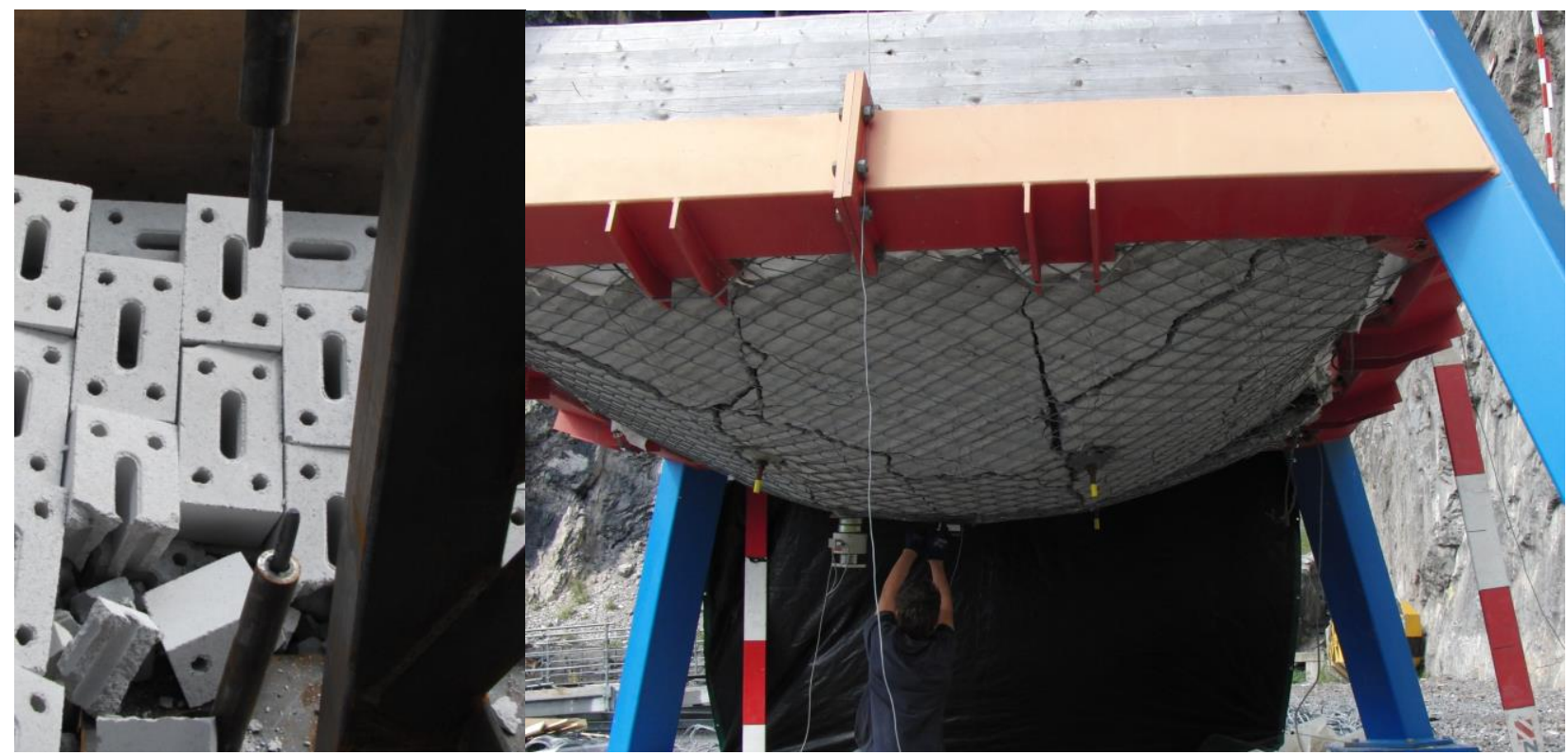

(a)

(b)

Figure 7 (a) fully elongated and broken bolt; and (b) fully supported by mesh after five impacts in the same test setup

\subsubsection{Test results}

Using a drop height of approximately $1.95 \mathrm{~m}$ and the test block's weight of 6,280 $\mathrm{kg}$, the energy input in the system can be calculated to $120 \mathrm{~kJ}$. Depending on the stiffness of the test setup the energy absorbed by the mesh and bolts will vary. The stiffer the test setup, the more energy is absorbed by the bolts. This is analogous to rock types which do not break into small pieces during a seismic event. Rock masses that do break into small pieces have more load going into the mesh because these small blocks are ejected between the bolts into the mesh. For the mutli-impact test, a stiff setup was chosen to distribute most of the load to the bolts for the first impacts. It was assumed that the setup gets mechanically softer after several impacts as damage to the 'rock mass' is ongoing and therefore the load distribution changes. The increasing of the load on the mesh can be seen on the test results (Figures 8-12). This distribution is analysed in Section 3.5.

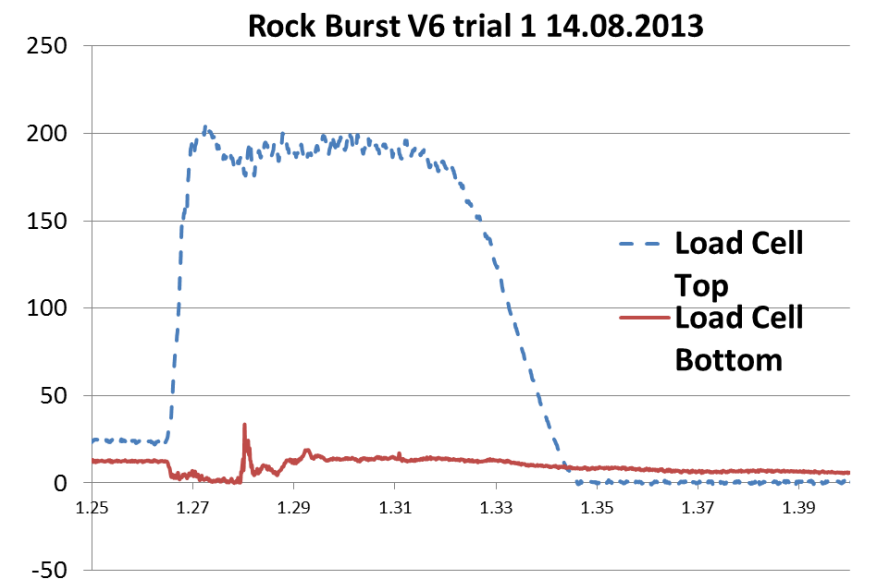

Figure 8 Forces measured by the load cells at impact one 


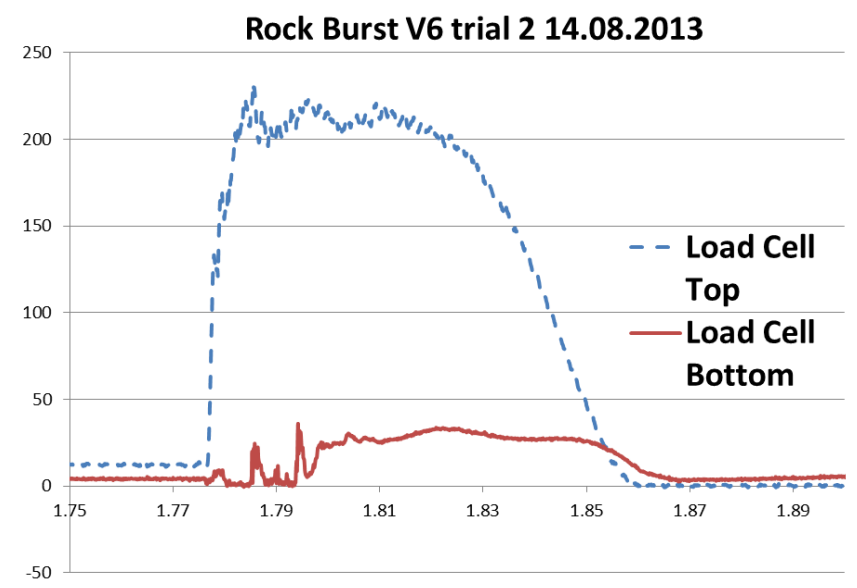

Figure 9 Forces measured by the load cells at impact two

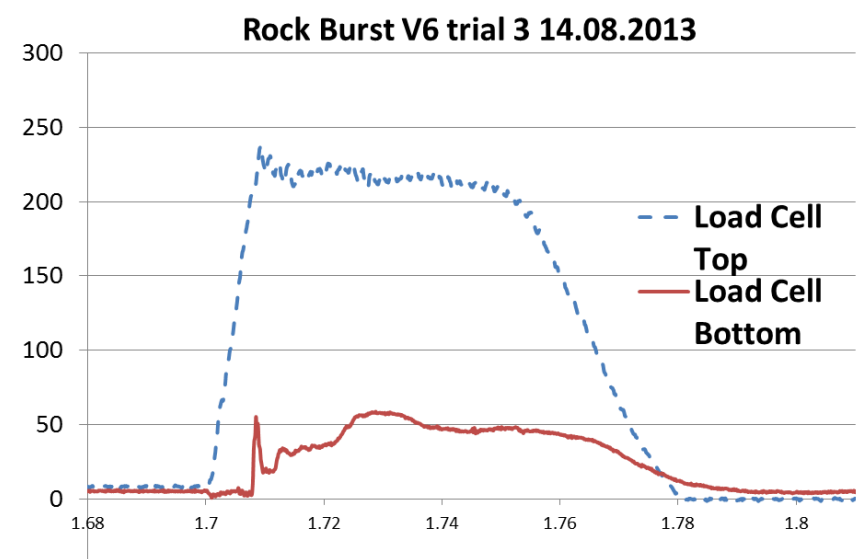

Figure 10 Forces measured by the load cells at impact three

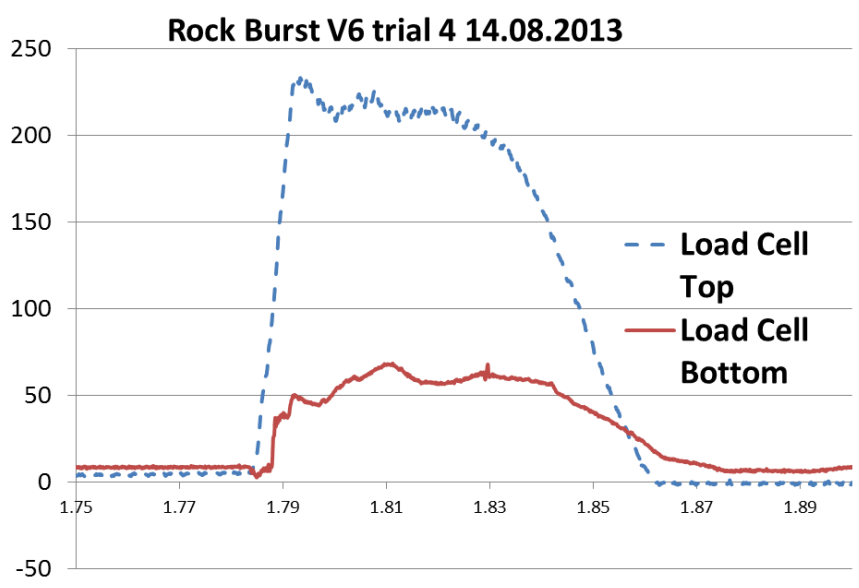

Figure 11 Forces measured by the load cells at impact four 


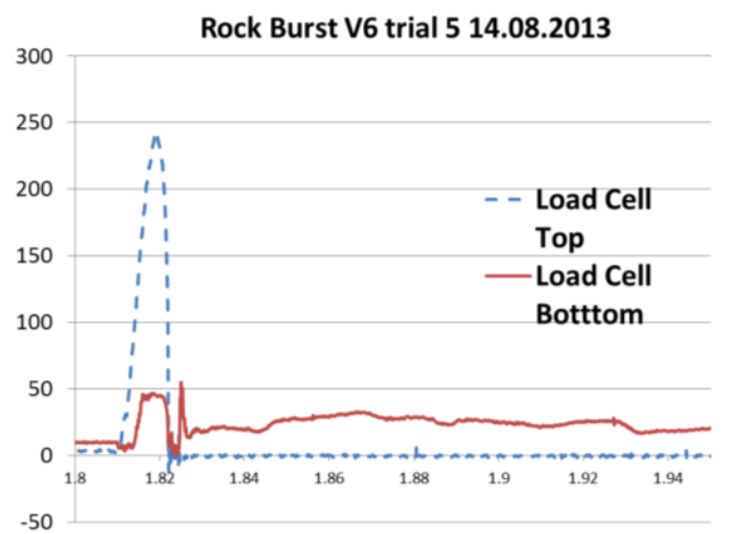

Figure 12 Forces measured by the load cells at impact five

Table 1 Deflection and forces measured

\begin{tabular}{ccccccc}
\hline Summary & Unit & Trial 1 & Trial 2 & Trial 3 & Trial 4 & Trial 5 \\
\hline Falling height & $\mathrm{m}$ & 1.91 & 1.93 & 1.90 & 1.90 & 1.90 \\
Theoretical pre-impact velocity & $\mathrm{m} / \mathrm{s}$ & 6.12 & 6.15 & 6.11 & 6.11 & 6.11 \\
Pre-impact velocity boulder from video & $\mathrm{m} / \mathrm{s}$ & 6.25 & 6.15 & 6.05 & 6.7 & 6.7 \\
Dynamic deflection of net centre from video & $\mathrm{cm}$ & 13 & $>11$ & 10 & 11 & $>23$ \\
Dynamic deflection - left front anchor & $\mathrm{cm}$ & 7 & 4 & 6 & 6 & $>23$ \\
Dynamic deflection - right anchor & $\mathrm{cm}$ & $>8$ & 6 & 4 & 5 & $>23$ \\
Dynamic deflection load cell & $\mathrm{cm}$ & 7 & 6 & 6 & 6 & $>20$ \\
Maximum load - cell 16 (top) & $\mathrm{kN}$ & 205 & 220 & 228 & 231 & 236 \\
Maximum load - cell 17 (bottom) & $\mathrm{kN}$ & 16 & 33 & 58 & 68 & 45 \\
\hline
\end{tabular}

\subsection{Analysis}

As described previously, the trials show that bolts and mesh work together, meaning that both support elements absorb a part of the energy without being overloaded. The amount of energy each part of the support will absorb depends on the type, stiffness and the behaviour of the rock mass.

The energy distribution in the stiff test setup using the integration of the load-displacement has been back-calculated as follows. The energy absorbed by the bolts is for the first four impacts about $40 \mathrm{~kJ}$ in total (about $10 \mathrm{~kJ}$ per bolt). The mesh absorbed about 12-14 kJ during first two impacts and up to $18 \mathrm{~kJ}$ for impacts number three and four. In this setup a total amount of 52-62 kJ was absorbed by the support system where the bolts took $78-70 \%$ and the mesh $22-30 \%$.

At impact number five all bolts broke and only the mesh was supporting the structure successfully. High mesh deformation was the result of missing bolt support. By knowing the energy dissipated by mesh and bolts, the energy absorbed by the test facility can be back-calculated. By subtracting the energy dissipated by the bolts and mesh, the leftover amount of energy refers to the energy absorbed by the test setup.

\subsection{Energy distribution between mesh and bolts}

The energy distribution on both support elements in regards to the stiffness of the test setup can be described by a simple model. The distribution of the load between reinforcement and surface support could be described by using a ratio of the mass or energy distribution between mesh and bolts. The rock mass acting directly on the bolts will have a cone shape around the bolts. Between the bolts, arching 
effects are observed, meaning that the mass above the arch loads the bolt as well as the cone. The rock mass below the arch will then impact the surface support.

For further considerations, the ratio can be estimated by evaluating the properties and the behavior of the rock mass. A stiffer rock mass which does not disintegrate much during a rockburst results in more mass and energy which have to be absorbed by the bolts. If the rock mass breaks into quite small pieces then a bigger share of the mass and energy is going on the mesh. It has to be kept in mind that rockburst events primarily occur in relatively high stressed brittle rock. Thus a too heavily broken up rock mass is unlikely.

The results of the two tests presented suggest that in a rock mass where the rock is not breaking into small pieces an energy distribution of $25 \%$ mesh and $75 \%$ bolt can be assumed. If the rock breaks into smaller pieces then this can be the opposite: Energy distribution of $70 \%$ mesh and $30 \%$ bolt. This ratio will also vary with the magnitude of the rockburst loading. The higher the loading the more mass has to be activated and the deeper the failure zone in the rock which consequently leads to an increase of the energy share for the bolts.

\section{$4 \quad$ Numerical modelling}

Numerical modelling of such sophisticated dynamic phenomena is a very complicated task. It is very difficult to validate a fully three-dimensional model including the dynamic interaction of an applied reinforcement system with the test facility. It is not a problem to simulate individual elements, but how to combine it all together to simulate the real process of the impact and facility reaction is a real challenge. The stiffness of the steel frame, filling material (gravel or limestone bricks), dumping at the boundary conditions, interface between all the neighbouring elements, are only a few of the problems to solve. The validation process of the full 3D model is still not completed.

Simplified 3D numerical models were developed to study the energy absorption by the mesh. All the calculations were performed with the finite difference code FLAC3D (Itasca Consulting Group, Inc. 2012). The mesh itself was modelled by pile-type structural elements. These are two-noded, straight, finite elements with six degrees of freedom per node. The mechanical properties of pile elements are given in Table 2.

Table 2 The mechanical properties of a pile element, assumed for numerical calculations

\begin{tabular}{cc}
\hline Pile element property & Value \\
\hline Young's modulus (GPa) & 210 \\
Poison's Ratio & 0.2 \\
Area $\left(\mathrm{mm}^{2}\right.$ ) & 12.56 \\
Plasticity limit (kN) & 22.2 \\
\hline
\end{tabular}

The $3.6 \times 3.6 \mathrm{~m}$ mesh square was fixed on each side and stressed by increasing static loading equal to the maximum dynamic load measured during the test. Three different test configurations were simulated. The details of the measured values for these tests are presented in Table 3.

Table 3 The measured values for three different tests

\begin{tabular}{cccc}
\hline Test number & $\begin{array}{c}\text { Dynamic mesh } \\
\text { deflection }(\mathbf{m m})\end{array}$ & $\begin{array}{c}\text { Static mesh } \\
\text { deflection }(\mathbf{m m})\end{array}$ & $\begin{array}{c}\text { Axial force in the } \\
\text { bottom load cell }(\mathbf{k N})\end{array}$ \\
\hline RBV1 & 724 & 699 & $100-105$ \\
RBV2 & 308 & 294 & 84 \\
RBV3 & 266 & 221 & 50 \\
\hline
\end{tabular}


The static loading mode was selected for purposes of simplification. Two different cases were modelled. In case one, the point loads (placed in the bolt's location) were applied in four points of the mesh. The loads were gradually increased up to the range of the measured displacement.

The example displacement map for the test RBV1 is presented in Figure 13. The undesirable 'belly effect' between four force points can be easily observed. The measured mesh displacement for this case was between $699 \mathrm{~mm}$ (static) to $724 \mathrm{~mm}$ (dynamic). The highest displacement obtained from numerical calculations was equal to $448 \mathrm{~mm}$. At this displacement the pile elements achieved their plastic limit and started to plastically deform. For the tests RBV2 and RBV3 the plastic limits were not reached, but increasing axial forces up to the measured results from the bottom load cell, resulted in displacements somehow different to measured ones. The detailed numerical simulation results are presented in Table 4.

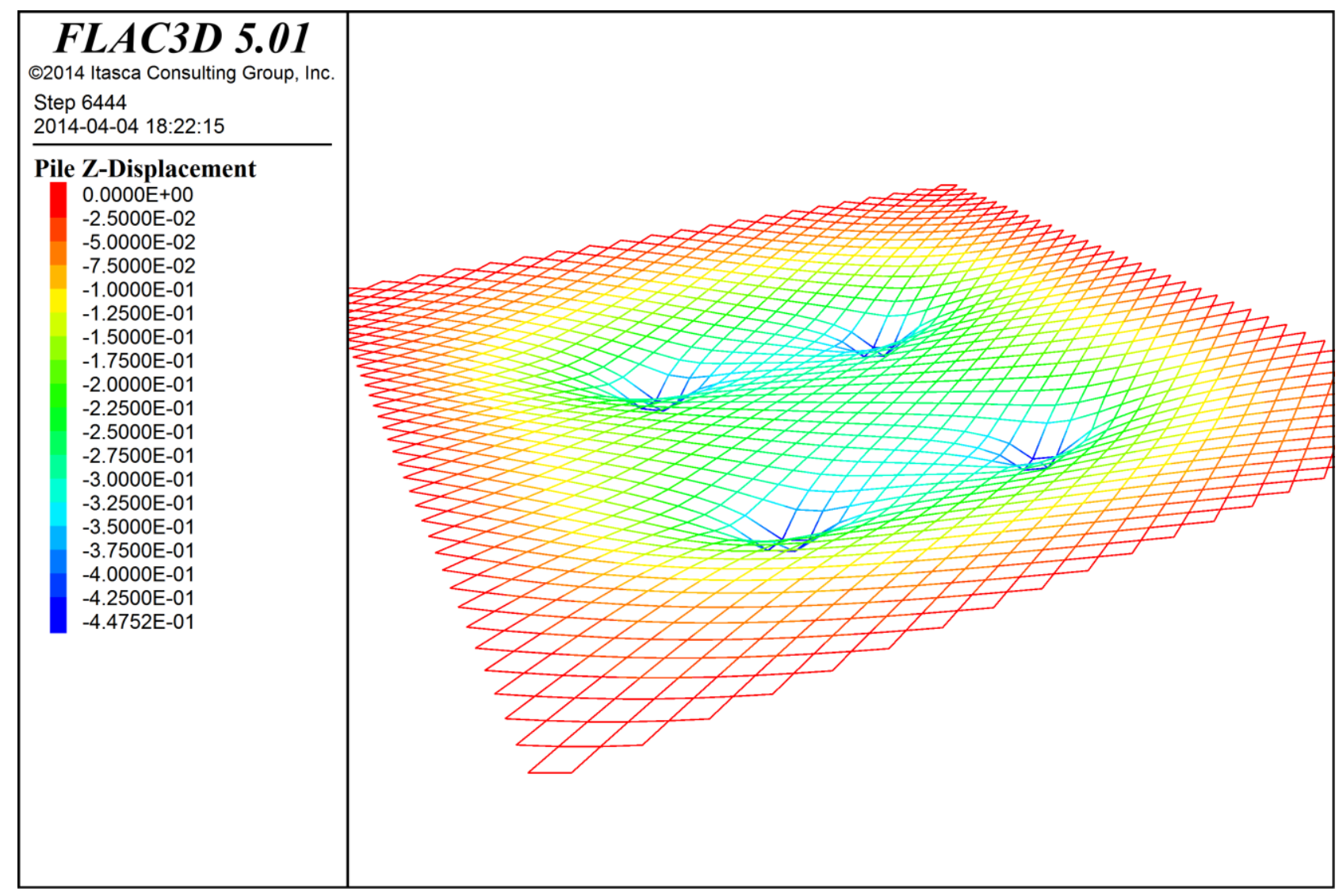

Figure 13 Displacement map for the test RBV1 - the point load case

Table 4 The calculated values for three different tests

\begin{tabular}{cccccc}
\hline Test number & \multicolumn{2}{c}{ Four point load case } & \multicolumn{2}{c}{ Uniform load (box) case } \\
& $\begin{array}{c}\text { Energy absorbed } \\
\text { by the mesh }(\mathbf{k J})\end{array}$ & $\begin{array}{c}\text { Mesh deflection } \\
(\mathbf{m m})\end{array}$ & $\begin{array}{c}\text { Energy absorbed by } \\
\text { the mesh (kJ) }\end{array}$ & $\begin{array}{c}\text { Mesh deflection } \\
(\mathbf{m m})\end{array}$ \\
\hline RBV1 & 80 & 448 & 147 & 503 \\
RBV2 & 43.7 & 349 & 33 & 288 \\
RBV3 & 12.4 & 229 & 17 & 237 \\
\hline
\end{tabular}


Due to the non-corresponding results of point loads compared to the field test results in case one, the second case was considered. The uniform, square load $(1.2 \times 1.2 \mathrm{~m}$, equal to the spacing of the bolts) was applied. And again, for the RBV1 test, the load was increased gradually up to the desired displacement. The modeled displacement level was slightly higher than for case one, $503 \mathrm{~mm}$. However again, pile elements reached their plastic limit and started to plastically deform. The displacement map for the test RBV1 is presented in Figure 14 (uniform load case). The displacement distribution is much smoother than for case one, and better corresponds to the real test result. The energy absorption levels are slightly different than in case one, and that also applies to mesh displacement (Table 4).

Two different cases simulated numerically produced variable results for mesh displacement and energy absorption levels. These results are generally in agreement with measured values (compare Table 3 and Table 4) but the numerical procedure is not satisfactory and does not simulate the test conditions properly. There may be several causes for this. First of all, the dynamic test is simulated in a quasi-static way, which forces quite a different response of the mesh to the dynamically loaded test. This is probably the key factor for successful numerical modelling. However it produces several problems like estimation of interface (contact) parameters between the mesh and the elements simulating dynamic impact. Another problem is the anisotropy of the mesh itself. For now it is only simulated as a rhomboidal mesh shape rather than individual wire elements.

The following experiments, planned to be done at the test facility, might be helpful in the elimination of problems discussed above. The concrete slab and brick pyramid will be eliminated. The reinforced concrete weight will be dropped straight on the mesh pinned to the frame and supported on four bolts. That should clarify the picture of the experiment and allow much easier construction of the numerical model.

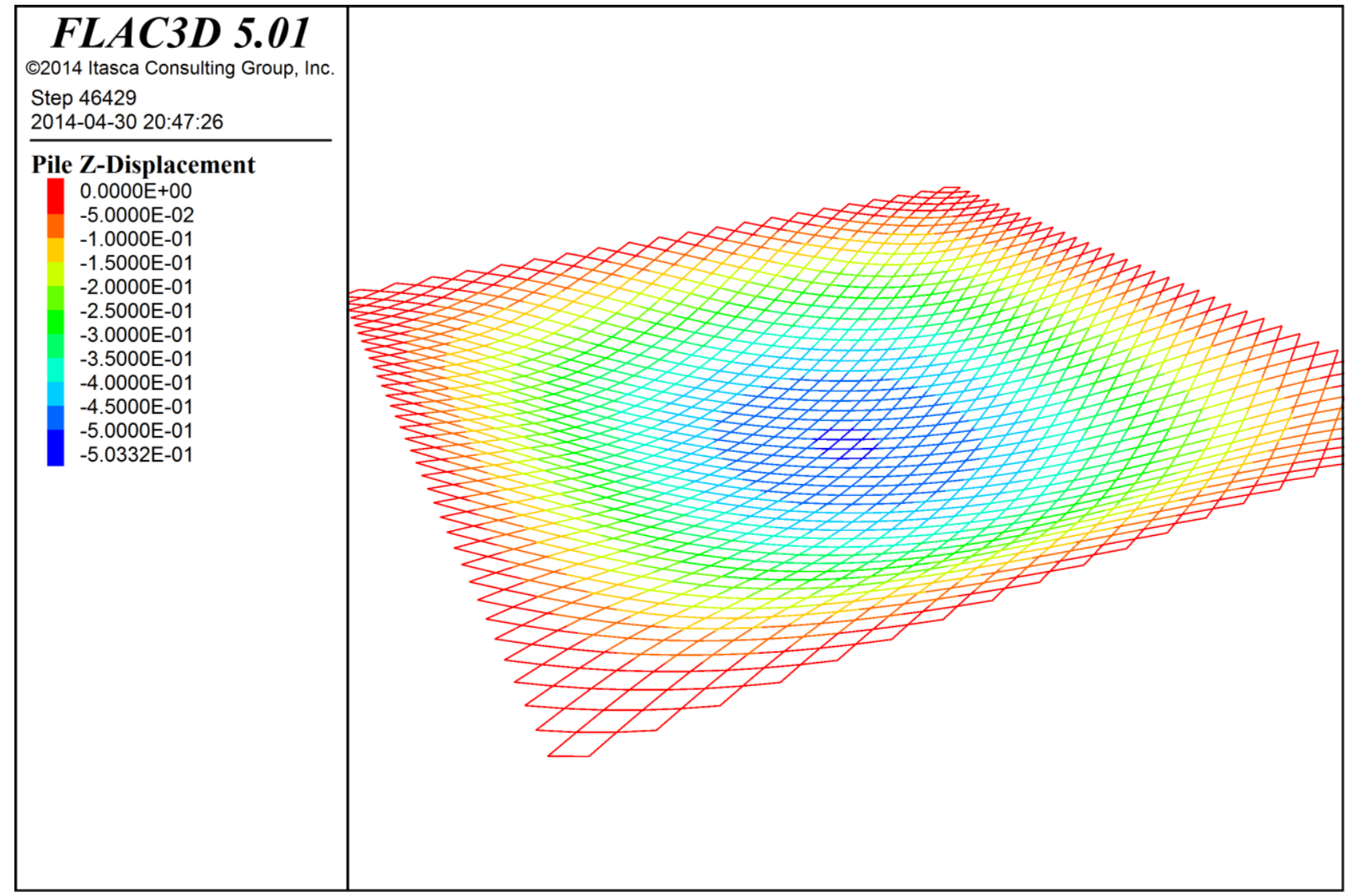

Figure 14 Displacement map for the test RBV1 - the uniform square load case 


\section{$5 \quad$ Conclusions and outlook}

It can be concluded that the test site Walenstadt has been successfully commissioned and that it can be used to apply a simulated dynamic rockburst loading to a larger panel of surface support and four bolts. The instrumentation with load cells, accelerometers and high speed video cameras does work as intended and allows an analysis and back-calculation of the system behaviour and energy absorption. With the stiff setup it was possible to show that the test setup can impose enough energy to activate four strong dynamic bolts. With the soft setup, mainly the mesh was loaded and the bolts were lightly activated. This result will lead to the next step in subjecting the setup to higher energies and thus simulate stronger rockbursts which should lead to the loading of the mesh and the yielding of the dynamic bolts.

The test setup proved to be suitable to show the overall performance of such a ground support system. It was demonstrated that high tensile mesh works together with the dynamic bolts. The method of connecting the two systems was shown to be suitable. However this test cannot be compared to more repeatable lab testing since it includes breakage of the concrete slab and also the compaction of the rock mass.

Based on this initial work it is hoped to be able to suggest a dimension factor for different ground conditions with a proven ratio of load which has to be absorbed by the surface support during a dynamic impact. This load then has to be transferred by the plate into the bolt without puncturing around the plate. Together with this information it will be possible to choose a dynamic bolt for the surface support which yields before the surface support ruptures. These factors of the load distribution between mesh and bolts seem to be dependent on the rock type and the magnitude of the rockburst.

\section{References}

Cala, M \& Roth, A 2007, 'Application of steel wire mesh for ground support under rockburst hazard', Gornictwo i Geoinzynieria, vol. 31 b. 3/1, pp. 125-133 (in Polish).

Cala, M, Roth, A \& Roduner, A 2013, 'Large scale field tests of rock bolts and high-tensile steel wire mesh subjected to dynamic loading', in M Kwasniewski \& D Lydzba (eds), Proceedings of EUROCK 2013 - The 2013 ISRM International Symposium Rock Mechanics for Resources, Energy and Environment, CRC Press, Boca Raton, pp. 721-726.

Hadjigeorgiou, J \& Potvin, Y 2011, 'A critical assessment of dynamic rock reinforcement and support testing facilities', Rock Mechanics and Rock Engineering, vol. 44, pp. 565-578.

Heal, D 2010, 'Observations and analyses of incidences of rock burst damage in underground mines', PhD thesis, The University of Western Australia, Perth.

Heal, D, Hudyma, M \& Potvin, Y 2004, 'Assessing the in-situ performance of ground support systems subjected to dynamic loading', Proceedings of the Fifth International Symposium on Ground Support in Mining and Underground Construction, E Villaescusa \& Y Potvin (eds), Balkema, Rotterdam, pp. 319-326.

Itasca Consulting Group, Inc. 2012, FLAC3D, Itasca Consulting Group, Inc., Minneapolis, http://www.itascacg.com/software/flac3d Kaiser, PK, Tannant, DD \& McCreath, DR 1996, Canadian Rockburst Support Handbook, Geomechanics Research Centre, Sudbury.

Player, JR, Villaescusa, E \& Thompson, AG 2004, 'Dynamic testing of rock reinforcement using momentum transfer concept', in E Villaescusa \& Y Potvin (eds), Proceedings of the Fifth International Symposium on Ground Support in Mining and Underground Construction, Balkema, Rotterdam, pp. 327-339.

Potvin, Y 2012, 'An interpretation of ground support capacity submitted to dynamic loading', Australian Centre for Geomechanics Newsletter, vol. 39, pp. 1-5. 
